\title{
Plants used in folk medicine: The potential of their hydromethanolic extracts against Candida species
}

\author{
Natália Martins ${ }^{\mathrm{a}, \mathrm{b}}$, Isabel C.F.R. Ferreira ${ }^{\mathrm{b}, *}$, Lillian Barros ${ }^{\mathrm{b}}$, Ana Maria Carvalho ${ }^{\mathrm{b}}$, \\ Mariana Henriques ${ }^{a}$, Sónia Silva ${ }^{a, *}$ \\ a CEB, Centre of Biological Engineering, LIBRO-Laboratório de Investigação em Biofilmes Rosário Oliveira, University of Minho, 4710057 Braga, Portugal \\ ${ }^{\mathrm{b}}$ Mountain Research Centre (CIMO), ESA, Polytechnic Institute of Bragança, Campus de Santa Apolónia, Apartado 1172, 5301855 Bragança, Portugal
}

\section{A R T I C L E I N F O}

\section{Article history:}

Received 13 October 2014

Received in revised form 2 December 2014

Accepted 16 December 2014

\section{Keywords:}

Medicinal plants

Hydromethanolic extracts

Antifungal activity

Candida species

\begin{abstract}
A B S T R A C T
Currently, opportunistic fungal infections are considered a serious problem regarding public health. Despite the advances towards the synthesis of new antifungal agents, an increasing incidence of drugresistant microorganisms has been observed. In this sense, other alternatives are necessary. In the present work, the antifungal activity of extracts from ten different plants, commonly used in folk medicine, were evaluated against nineteen Candida strains, including C. albicans, C. glabrata, C. parapsilosis and C. tropicalis species. Although the majority of the extracts had no antimicrobial effect, Juglans regia extract was very effective, exerting an inhibitory effect against all the tested Candida strains, while Eucalyptus globulus was effective against seventeen of them. Pterospartum tridentatum and Rubus ulmifolius presented similar antifungal effects, being effective against six Candida strains. The diameter of halo ranged, respectively, between 9-14 $\mathrm{mm}$ and 9-21 mm to the mentioned plant extracts, and the $\mathrm{MIC}_{50}$ values evidenced mainly a fungistatic activity. Both extracts showed similar $\mathrm{MIC}_{50}$ values for $C$. albicans strains, while $C$. parapsilosis and $C$. glabrata were more sensible to E. globulus. Otherwise, all the $C$. tropicalis strains were more sensible to J. regia. Overall, hydromethanolic plant extracts could constitute promissory alternatives to the traditional antifungal agents.
\end{abstract}

(C) 2014 Elsevier B.V. All rights reserved.

\section{Introduction}

Medicinal plants have been widely used, since pre-historic era, not only to improve health and well-being, but also to treat some specific diseases/disorders (Agarwal et al., 2010; Bakkali et al., 2008; Sher, 2009). In the last years, those natural matrices have sparked an increasing interest for scientific researchers, who have proved their extremely richness in natural biomolecules, conferring a multitude of biological properties. Their phytochemical potential, synergistic effects and mechanisms of action have been studied, in different areas of knowledge (Alves-Silva et al., 2013; Shojaii and Fard, 2012; Singh et al., 2010). However, many extracts/compounds from plant origin remain unstudied.

In parallel with these advances on plant products research, microbiological area has been subjected to severe modifications. A wide variety of microorganisms exist in the commensal flora of healthy population, providing several benefits to the host. How-

\footnotetext{
* Corresponding author. Tel.: +351 273303219/53604401;

fax: +351 273325405/53604429.

E-mail addresses: iferreira@ipb.pt, soniasilva@deb.uminho.pt (S. Silva).
}

ever, in the last two decades, some species have presented an abnormal overgrowth and they become harmful, affecting directly not only the welfare, but also the life of individuals (Kim and Sudbery, 2011; Mayer et al., 2013; Tsai et al., 2013).

Opportunistic fungal infections, namely Candida species, comprise the most common deep pathogenic infections, being observed not only in immunocompromised patients, but also around the hospital and even in the rest of the population (Abi-Said et al., 1997; Eggimann et al., 2003; Li et al., 2006; Raman et al., 2013). Candida albicans has been considered the most relevant species in the mentioned infections, nevertheless, other Candida species have been, currently, pointed out, such as Candida tropicalis, C. glabrata, C. dubliniensis, C. parapsilosis, C. orthopsilosis, C. metapsilosis, C. krusei, C. famata, C. guilliermondii and C. lusitaniae (Brunke and Hube, 2013; Ferreira et al., 2013; Kim and Sudbery, 2011; Mayer et al., 2013; Sardi et al., 2013).

Concomitantly, increasing rates of drug-resistant pathogenic microorganisms have been observed, in part due to the indiscriminate use of some antimicrobial agents (Kanafani and Perfect, 2008; Sangamwar et al., 2008; Sanglard and Odds, 2002; Sanglard, 2002; White et al., 1998). Some advances in pharmaceutical industries have been achieved, towards the synthesis and/or preparation of 
Table 1

Antifungal activity of hydromethanolic extracts from different plant origin, against several Candida species.

\begin{tabular}{|c|c|c|c|c|c|c|c|c|c|c|c|c|}
\hline \multirow[b]{2}{*}{ Species } & \multirow[b]{2}{*}{ Strains } & \multirow[b]{2}{*}{ Origin } & \multicolumn{10}{|c|}{ Inhibition zones $(\mathrm{mm})$} \\
\hline & & & $\begin{array}{l}\text { Echinacea } \\
\text { purpurea }\end{array}$ & $\begin{array}{l}\text { Eucalyptus } \\
\text { globulus }\end{array}$ & $\begin{array}{l}\text { Foeniculum } \\
\text { vulgare }\end{array}$ & $\begin{array}{l}\text { Juglans } \\
\text { regia }\end{array}$ & $\begin{array}{l}\text { Matricaria } \\
\text { recutita }\end{array}$ & $\begin{array}{l}\text { Melissa } \\
\text { officinalis }\end{array}$ & $\begin{array}{l}\text { Pterospartum } \\
\text { tridentatum }\end{array}$ & Rosa canina & $\begin{array}{l}\text { Rubus } \\
\text { ulmifolius }\end{array}$ & $\begin{array}{l}\text { Tabebuia } \\
\text { impetiginosa }\end{array}$ \\
\hline \multirow[t]{4}{*}{ C. albicans } & ATCC 90028 & Reference & - & 10 & - & 13 & - & - & 10 & - & 10 & - \\
\hline & 575541 & Urinary & - & 12 & - & 13 & - & - & - & - & 9 & - \\
\hline & 557834 & Vaginal & - & 12 & - & 12 & - & + & 10 & ++ & 10 & - \\
\hline & 558234 & Vaginal & - & 11 & - & 12 & - & - & 9 & - & 15 & ++ \\
\hline \multirow[t]{3}{*}{ C. glabrata } & ATCC 2001 & Reference & - & 21 & - & 14 & - & - & 11 & - & 19 & - \\
\hline & D1 & Oral & - & 13 & - & 12 & - & - & 11 & - & ++ & - \\
\hline & 513100 & Urinary & - & 11 & - & 10 & - & - & 9 & - & 16 & - \\
\hline \multirow{5}{*}{ C. parapsilosis } & ATCC 22019 & Reference & ++ & 10 & ++ & 12 & _- & _- & ++ & _- & - & _- \\
\hline & AM2 & Oral & - & 9 & - & 12 & - & - & ++ & - & ++ & - \\
\hline & $\mathrm{AD}$ & Oral & - & 18 & - & 12 & - & - & - & - & + & + \\
\hline & 491861 & Vaginal & - & + & ++ & 11 & +++ & - & - & - & ++ & +++ \\
\hline & 513143 & Vaginal & - & 12 & - & 10 & + & - & - & - & - & - \\
\hline \multirow[t]{7}{*}{ C. tropicalis } & ATCC 750 & Reference & - & 13 & - & 11 & - & - & + & - & - & - \\
\hline & AG1 & Oral & - & 11 & ++ & 12 & _- & - & +++ & - & - & - \\
\hline & 75 & Vaginal & - & 12 & - & 10 & - & - & - & - & ++ & - \\
\hline & 12 & Vaginal & - & +++ & - & 9 & - & - & - & - & - & - \\
\hline & 544123 & Urinary & - & 9 & - & 10 & - & - & - & - & - & - \\
\hline & 519468 & Urinary & - & 10 & - & 10 & - & - & - & - & - & - \\
\hline & $\mathrm{T} 2.2$ & Oral & - & 9 & - & 10 & - & - & - & - & - & - \\
\hline
\end{tabular}

(-) Absence of antifungal effect, (+) cell growth inhibition, (++) cell density reduction, (+++) cell density reduction and growth inhibition. 
new antifungal drugs more effective and selective than the previous (Perlin, 2014, 2009; Sangamwar et al., 2008), but, some crucial aspects need to be considered, such as their safety, tolerability and even side effects. Recent studies have been carried out accessing the antifungal potential of some plant species, but essential oils are the main used extract preparations. Despite the existence of other solvents that have also been used in extraction procedures (i.e., ethanol, alcohol, methanol, ethyl acetate, dichloromethane, water, among others), some evidences show that when a small portion of water is added to the organic solvent, the phenolic extraction is improved. Therefore, considering that natural extracts/compounds from plant origin could play an important role in the development of antifungal agents, the aim of the present work is to identify and highlight the potential of hydromethanolic extracts prepared from ten different plants commonly used in folk medicine against Candida species.

\section{Materials and methods}

\subsection{Samples}

A total of ten medicinal plants, commonly used in folk medicine, were studied; four were wild harvested in Trás-os-Montes Bragança, North-Eastern Portugal: flower buds and fully opened flowers of Rubus ulmifolius Schott (elm-leaved blackberry), petals of Rosa canina L. (rose hips/dogrose), and leaves of Juglans regia L. (walnut). The other seven were commercial samples: leaves of Melissa officinalis L. (lemonbalm), aerial parts of Foeniculum vulgare Miller (fennel), Matricaria recutita L. (chamomile) and Echinacea purpurea (L.) Moench (purple coneflower), and leaves of Eucalyptus globulus Labill. (blue gum), Tabebuia impetiginosa (Mart. ex DC) Standley (pau d'arco) and flowering parts of Pterospartum tridentatum (L.) Willk. (carqueja). Plant scientific nomenclature according to The Plant List (2013), version 1.1 (2013).

\subsection{Standards and reagents}

Methanol was of analytical grade purity and supplied by Pronalab (Lisbon, Portugal). RPMI 1640 medium was purchased from Sigma Chemical Co., (St. Louis, MO, USA). Sabouraud Dextrose Broth (SDB) and Agar were from Merck (Darmstadt, Germany). Water was treated in a Milli-Q water purification system (TGI Pure Water Systems, Greenville, SC, USA).

\subsection{Preparation of the hydromethanolic extracts}

Hydromethanolic extracts were obtained by extracting the sample $(1 \mathrm{~g})$ with $30 \mathrm{~mL}$ of methanol:water $(80: 20, v / v)$ at $25^{\circ} \mathrm{C}$ and $150 \mathrm{rpm}$ for $1 \mathrm{~h}$, and filtering through Whatman No. 4 paper. The final residue was then extracted with an additional $30 \mathrm{~mL}$ portion of the hydromethanolic mixture. The combined extracts were evaporated at $35^{\circ} \mathrm{C}$ under reduced pressure (rotary evaporator Büchi R-210, Flawil, Switzerland) and then lyophilized (FreeZone 4.5, Labconco, Kansas City, MO, USA). The lyophilized hydromethanolic extracts, were re-dissolved in water, performing stock solutions with concentrations of $50 \mathrm{mg} / \mathrm{mL}$, from which several dilutions were prepared.

\subsection{Antifungal activity}

\subsubsection{Disc diffusion assay}

Nineteen Candida strains were used during this study (Table 1), four from the American Type Culture Collection (ATCC), and fifteen clinical isolates from vaginal and urinary tracts and oral cavity. The clinical isolates were obtained from the archive collection of the biofilm group of the Centre of Biological Engineering, University of
Minho, Braga - Portugal. Before each experiment, all strains were grown in Sabouraud Dextrose Agar (SDA) for $24 \mathrm{~h}$ at $37^{\circ} \mathrm{C}$. After that time, one loop of each colony of cells was transferred to SDB liquid medium and incubated under stirring at $37^{\circ} \mathrm{C}$ during $24 \mathrm{~h}$. An aliquot of each species ( $300 \mu \mathrm{L})$, containing approximately $1 \times 10^{5}$ cells/mL was spread in SDA Petri dishes. Then, an aliquot $(25 \mu \mathrm{L})$ of each hydromethanolic plant extracts, with a known concentration $(50 \mathrm{mg} / \mathrm{mL})$, was placed on a sterile blank disc. Sterile water was used as negative control. The plates were incubated at $37^{\circ} \mathrm{C}$, during $24-48 \mathrm{~h}$. The evaluation of inhibitory properties was performed measuring the corresponding zone of inhibition. However, when there was no evident halo, but some inhibition of growth, the effect was also classified as: (+) cell growth inhibition, $(++)$ cell density reduction, $(+++)$ cell density reduction and growth inhibition.

\subsubsection{Minimal inhibitory concentrations (MIC)}

Minimal inhibitory concentrations were determined for the plant extracts that demonstrated the most pronounced positive results in the disc diffusion test, according with the guidelines from the Nature Protocols (Wiegand et al., 2008), with some modifications. Afterwards, a colony recovered from the SDA was suspended in $5 \mathrm{~mL}$ of sterile saline solution $(0.85 \% \mathrm{NaCl})$ and vortexed for $15 \mathrm{~s}$. The resulting suspension was adjusted by adding saline solution to reach the value of 0.5 in McFarland scale. Successive dilutions of each plant extract $(0.1875,0.375,0.75$, and $1.5 \mathrm{mg} / \mathrm{mL})$ were prepared in RPMI 1640 medium at $\mathrm{pH} 7$. Aliquots of each plant extract $(100 \mu \mathrm{L})$, were dispensed into a 96-well plates (Orange Scientific, Braine-l'Alleud, Belgium) and further incubated with aliquots $(100 \mu \mathrm{L})$ of the tested Candida species. Sample and yeast-free controls were also included. The 96 -well plates were incubated at $37^{\circ} \mathrm{C}$ for $48 \mathrm{~h}$. After visualization of the resultant plate, the MIC values were correspondent to the antifungal concentration where there was no growth, or even fungistatic effect, by comparison with the control (cells grown without extracts). The number of viable cells was assessed by the determination of number of colony forming units (CFUs), through several dilutions, after $24 \mathrm{~h}$ of incubation at $37^{\circ} \mathrm{C}$ and the number of colonies formed were counted. The results were presented as the total of CFUs (Log CFUs) and the experiments were repeated in triplicate on three different occasions.

\subsection{Statistical analysis}

The results were analyzed using one-way analysis of variance (ANOVA) and means were compared using Tukey's honestly significant difference (HSD) multiple comparisons test and further coupled to Welch to verify the equality of means. All statistical tests were performed using IBM SPSS Statistics for Windows, version 22.0. (IBM Corp., USA).

\section{Results and discussion}

The results of the antifungal activity screening of the tested hydromethanolic extracts, against nineteen Candida strains are presented in Table 1. No evident halo formation was observed for Echinacea purpurea, Foeniculum vulgare, Matricaria recutita, Melissa officinalis, Rosa canina and Tabebuia impetiginosa, while in Eucalyptus globulus, Juglans regia, Pterospartum tridentatum and Rubus ulmifolius plant extracts, the halo diameters ranged between 9-21 mm. Juglans regia extract was the most effective one, presenting an evident halo for all the tested Candida strains (varying between 9-14 mm). Eucalyptus globulus extract also presented a significant antifungal potential, being effective against seventeen Candida strains (diameter of halo ranging between 9-21 mm). Pterospartum tridentatum and Rubus ulmifolius presented similar antifungal effects, being effective against six Candida strains, 


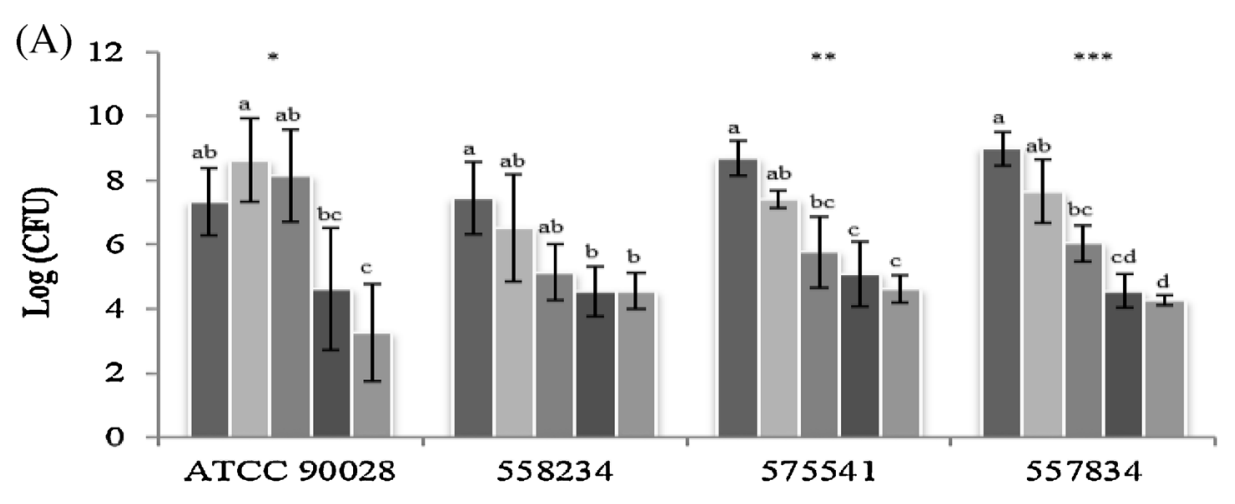

Candida albicans strains

(B)

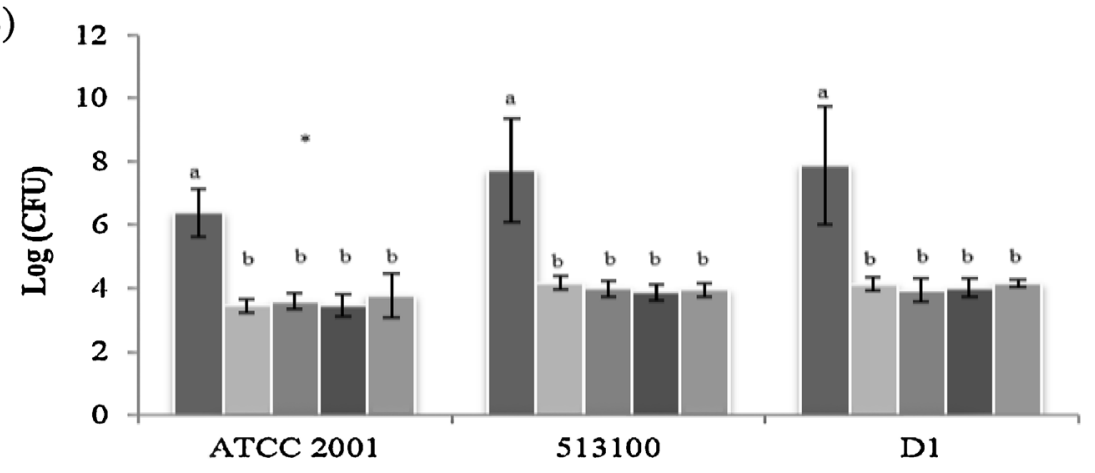

Candida glabrata strains

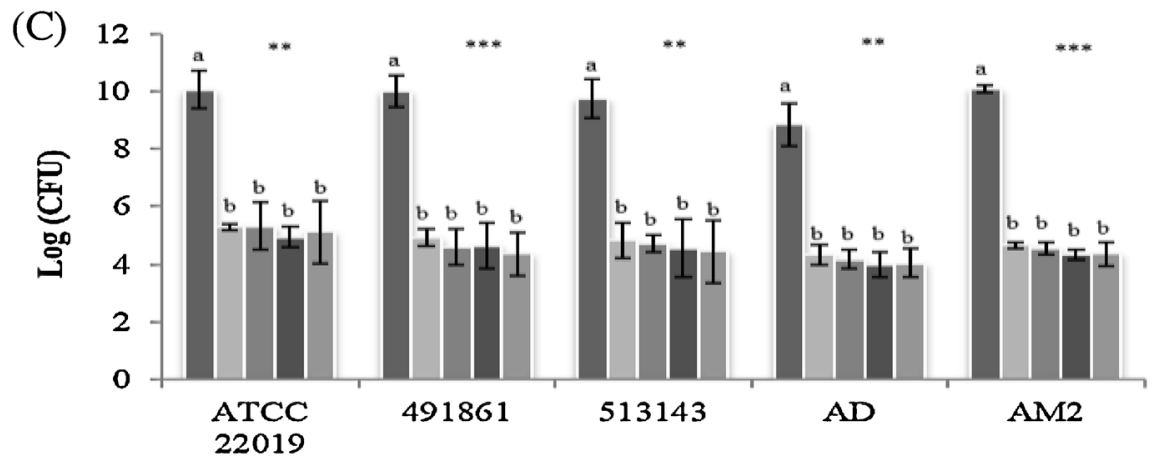

Candida parapsilosis strains

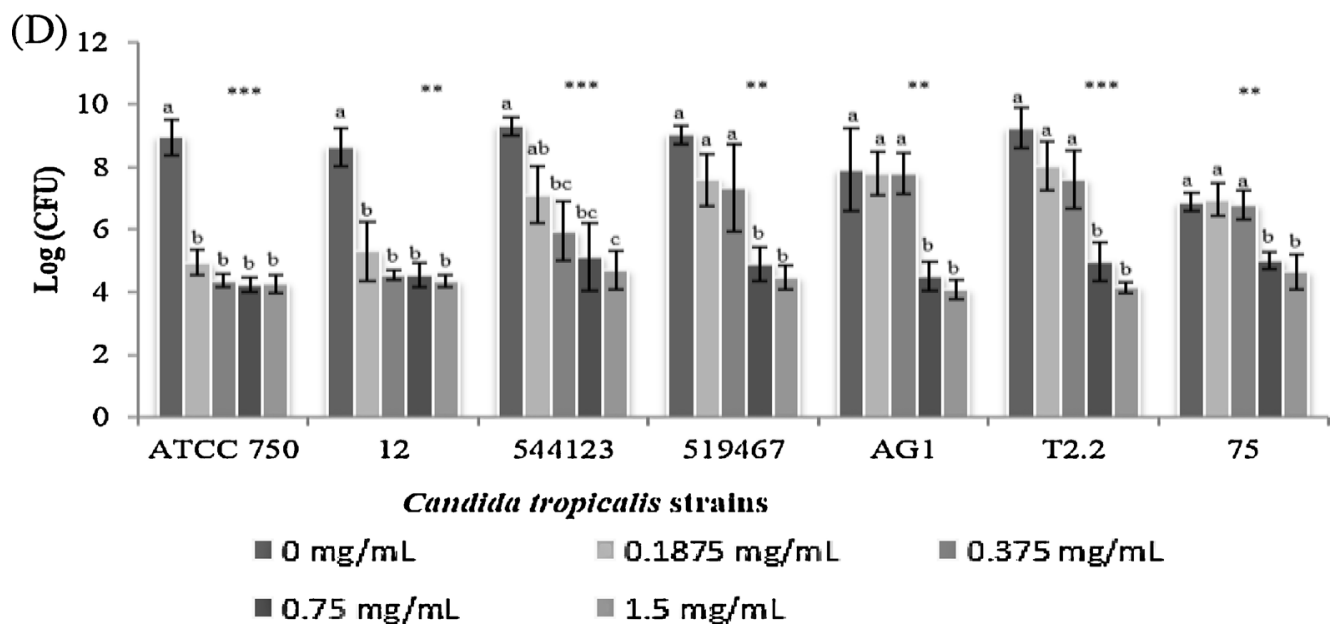

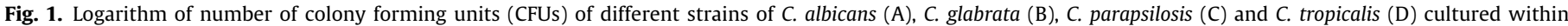

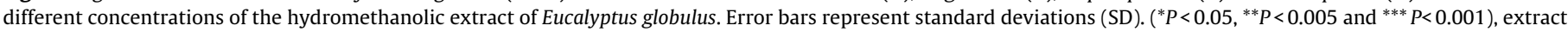
concentrations results that are significantly different. In each strain different letters mean significant differences $(P<0.05)$. 

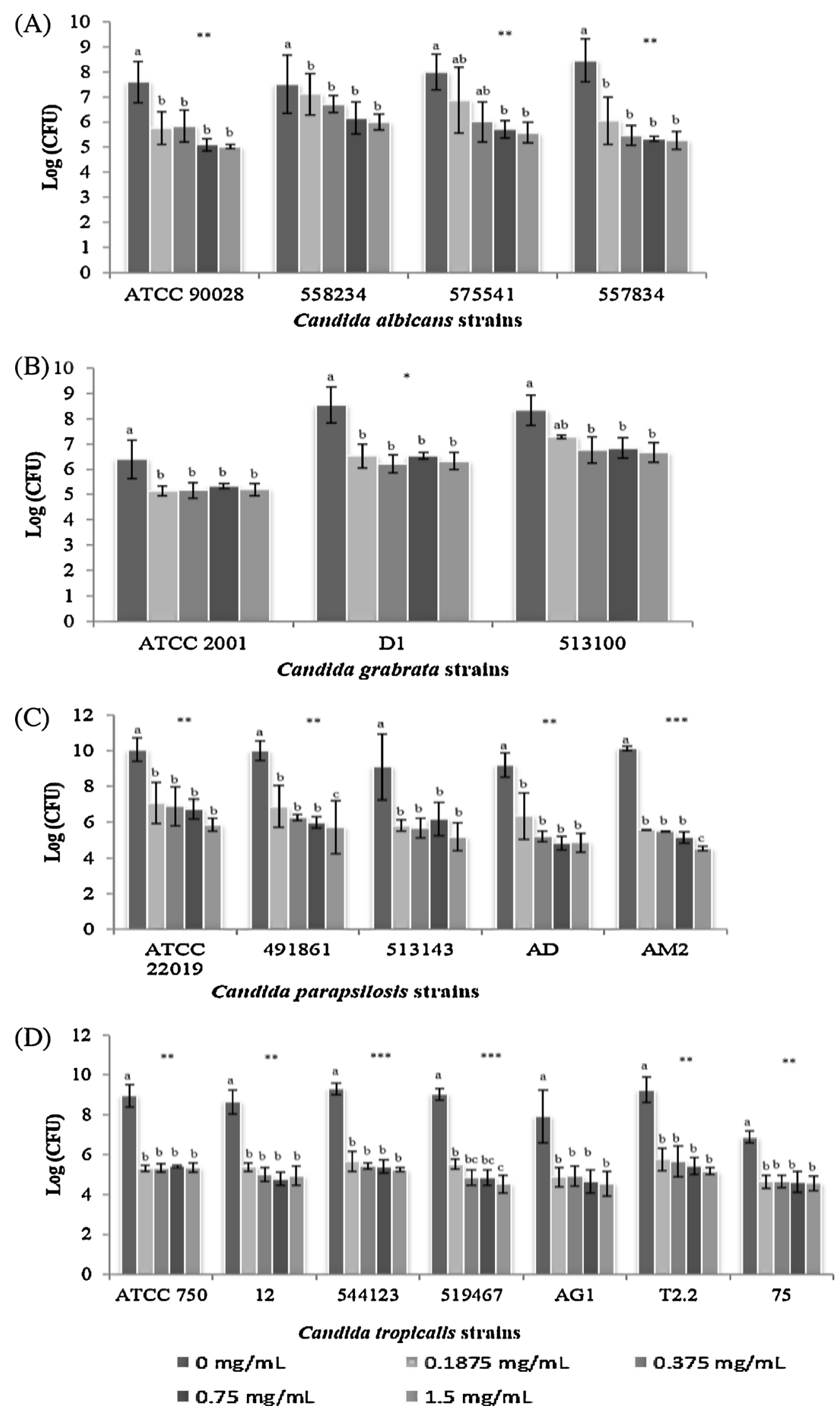

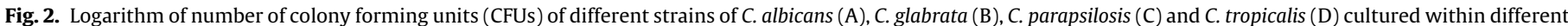

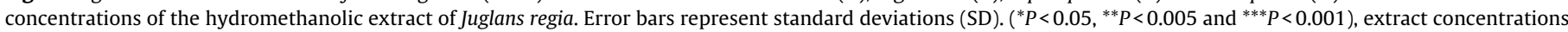
results that are significantly different. In each strain different letters mean significant differences $(P<0.05)$. 
belonging to $C$. albicans, $C$. glabrata and C. parapsilosis species. Moreover, the majority of $C$. tropicalis strains were resistant to both tested extracts. No evident antifungal activity was also observed for Rosa canina. This work revealed that, in general, C. glabrata strains were the most susceptible Candida species, followed by $C$. albicans, C. parapsilosis and, lastly, C. tropicalis strains.

Some previous reports have described the antimicrobial properties of those medicinal plants, namely Foeniculum vulgare essential oil (Roby et al., 2013), Melissa officinalis ethanol extract (Ertürk, 2006; Uzun et al., 2004), Rosa canina aqueous extract (Orhan et al., 2012), and Juglans regia methanol, ethyl acetate and acetone extracts (Noumi et al., 2011, 2010), remaining unstudied the hydromethanolic extract preparations. In fact, there are some evidences confirming the high diversity of chemical compounds solubility and, therefore, the extraction solvent affect the extracts bioactivity. In this sense, and in order to understand the effects of hydromethanolic extract preparations, minimal inhibitory concentrations were determined for the plant extracts that demonstrated positive results in the initial screening (Table 1).

Thus, the MIC values were determined for Eucalyptus globulus and Juglans regia extracts (Figs. 1 and 2, respectively) against C. tropicalis strains $(n=7), C$. parapsilosis strains $(n=5), C$. glabrata $(n=3)$ and $C$. albicans $(n=4)$. The obtained results revealed that both extracts exerted more fungistatic than fungicidal effect, since they only caused a considerable CFUs reduction, without evidences of a full growth inhibition. Moreover, all the obtained results are in accordance with the previous assay (disc diffusion assay). For example, E. globulus showed a growth reduction between 2 and 5 Log (CFUs), in all the tested C. parapsilosis $\left(\mathrm{MIC}_{50}=0.1875 \mathrm{mg} / \mathrm{mL}\right)$, followed by $C$. glabrata $\left(\mathrm{MIC}_{50}=0.1875 \mathrm{mg} / \mathrm{mL}\right.$ ) and some $C$. tropicalis strains, namely ATCC 750, 12, 544123, 519467 and T2.2 $\left(0.1875<\mathrm{MIC}_{50}<1.5 \mathrm{mg} / \mathrm{mL}\right)$. While those Candida species were the most sensible to E. globulus extract, $C$. albicans strains were less sensible $\left(\mathrm{MIC}_{50} \geq 1.5 \mathrm{mg} / \mathrm{mL}\right)$. Otherwise, for $J$. regia, the tested $C$. parapsilosis $\left(0.1875<\mathrm{MIC}_{50}<1.5 \mathrm{mg} / \mathrm{mL}\right)$ and $C$. tropicalis $\left(\mathrm{MIC}_{50} \approx 0.1875 \mathrm{mg} / \mathrm{mL}\right.$ ) strains were the most sensible. The Log CFUs reduction ranged between 3 and 5 , while for $C$. albicans $\left(\mathrm{MIC}_{50} \geq 1.5 \mathrm{mg} / \mathrm{mL}\right)$ and C. glabrata $\left(\mathrm{MIC}_{50} \geq 1.5 \mathrm{mg} / \mathrm{mL}\right)$ strains ranged between 0.5 and $2.5 \mathrm{Log}$ (CFUs), corresponding to a higher resistance.

Overall, and despite the need of further studies to elucidate the mechanisms of action of the tested plant extracts, as well as to test their in vivo efficacy, it is possible to conclude that hydromethanolic extracts of $E$. globulus and J. regia could constitute promissory alternatives to the current antifungal agents.

\section{Acknowledgements}

The authors are grateful to Foundation for Science and Technology (FCT, Portugal) for N. Martins grant (SFRH/BD/87658/2012), L. Barros researcher contract under "Programa Compromisso com Ciência - 2008" and financial support to the research centre CIMO (strategic project PEst-OE/AGR/UI0690/2011). This work was also supported by the Programa Operacional, Fatores de competitividade - COMPETE and by national funds through FCT - Fundação para a Ciência e a Tecnologia on the scope of the projects FCT PTDC/SAU-MIC/119069/2010, RECI/EBB-EBI/0179/2012 and PEstOE/EQB/LA0023/2013. The authors thank the Project "BioHealth Biotechnology and Bioengineering approaches to improve health quality", Ref. NORTE-07-0124-FEDER-000027, co-funded by the Programa Operacional Regional do Norte (ON.2 - O Novo Norte), QREN, FEDER. The authors are also grateful to "MaisErvas Aromáticas e Medicinais" and "Américo Duarte Paixão Lda. " for the supplying of some plant species.

\section{References}

Abi-Said, D., Anaissie, E., Uzun, O., Raad, I., Pinzcowski, H., Vartivarian, S., 1997. The epidemiology of hematogenous candidiasis caused by different Candida species. Clin. Infect. Dis. 24, 1122-1128.

Agarwal, V., Lal, P., Pruthi, V., 2010. Effect of plant oils on Candida albicans. J. Microbiol. Immunol. Infect. 43, 447-451.

Alves-Silva, J.M., Santos, S.M.D., Pintado, M.E., Pérez-Álvarez, J.A., Fernández-López, J., Viuda-Martos, M., 2013. Chemical composition and in vitro antimicrobial, antifungal and antioxidant properties of essential oils obtained from some herbs widely used in Portugal. Food Control 32, 371-378.

Bakkali, F., Averbeck, S., Averbeck, D., Idaomar, M., 2008. Biological effects of essential oils - a review. Food Chem. Toxicol. 46, 446-475.

Brunke, S., Hube, B., 2013. Two unlike cousins: Candida albicans and C. glabrata infection strategies. Cell. Microbiol. 15, 701-708.

Eggimann, P., Garbino, J., Pittet, D., 2003. Epidemiology of Candida species infections in critically ill non-immunosuppressed patients. Lancet Infect. Dis. 3 685-702.

Ertürk, Ö., 2006. Antibacterial and antifungal activity of ethanolic extracts from eleven spice plants. Biologia (Bratislava) 61, 275-278.

Ferreira, A.V., Prado, C.G., Carvalho, R.R., Dias, K.S.T., Dias, A.L.T., 2013. Candida albicans and non-C. albicans Candida species: comparison of biofilm production and metabolic activity in biofilms, and putative virulence properties of isolates from hospital environments and infections. Mycopathologia 175, 265-272.

Kanafani, Z.A., Perfect, J.R., 2008. Resistance to antifungal agents: mechanisms and clinical impact. Clin. Infect. Dis. - Antimicrob. Resist. 46, 120-128.

Kim, J., Sudbery, P., 2011. Candida albicans, a major human fungal pathogen. J. Microbiol. 49, 171-177.

Li, S.Y., Yang, Y.L., Chen, K.W., Cheng, H.H., Chiou, C.S., Wang, T.H., Lauderdale, T.L., Hung, C.C., Lo, H.J., 2006. Molecular epidemiology of long-term colonization of Candida albicans strains from HIV-infected patients. Epidemiol. Infect. 134, 265-269.

Mayer, F.L., Wilson, D., Hube, B., 2013. Candida albicans pathogenicity mechanisms. Virulence 4, 119-128.

Noumi, E., Snoussi, M., Hajlaoui, H., Valentin, E., Bakhrouf, A., 2010. Antifungal properties of Salvadora persica and Juglans regia L. extracts against oral Candida strains. Eur. J. Clin. Microbiol. Infect. Dis. 29, 81-88.

Noumi, E., Snoussi, M., Trabelsi, N., Hajlaoui, H., Ksouri, R., Valentin, E., Bakhrouf, A. 2011. Antibacterial, anticandidal and antioxidant activities of Salvadora persica and Juglans regia L. extracts. J. Med. Plants Res. 5, 4138-4146.

Orhan, D.D., Özçelikk, B., Hoşbaș, S., Vural, M., 2012. Assessment of antioxidant antibacterial antimycobacterial, and antifungal activities of some plants used as folk remedies in Turkey against dermatophytes and yeast-like fungi. Turkish J. Biol. 36, 672-686.

Perlin, D.S., 2009. Resistance to echinocandin-class antifungal drugs. Drug Resist. Updates 10, 121-130.

Perlin, D.S., 2014. Current perspectives on echinocandin class drugs. Future Microbiol. 6, 441-457.

Raman, S.B., Nguyen, M.H., Cheng, S., Badrane, H., Iczkowski, K.A., Wegener, M., Gaffen, S.L., Mitchell, A.P., Clancy, C.J., 2013. A competitive infection model of hematogenously disseminated candidiasis in mice redefines the role of Candida albicans IRS4 in pathogenesis. Infect. Immun. 81, 1430-1438.

Roby, M.H.H., Sarhan, M.A., Selim, K.A.-H., Khalel, K.I., 2013. Antioxidant and antimicrobial activities of essential oil and extracts of fennel (Foeniculum vulgare L.) and chamomile (Matricaria chamomilla L.). Ind. Crops Prod. 44, 437-445.

Sangamwar, A.T., Deshpande, U.D., Pekamwar, S.S., 2008. Antifungals: need to search for a new molecular target. Indian J. Pharm. Sci. 70, 423-430.

Sanglard, D., 2002. Resistance of human fungal pathogens to antifungal drugs. Curr Opin. Microbiol. 5, 379-385.

Sanglard, D., Odds, F.C., 2002. Reviews resistance of Candida species to antifungal agents: molecular mechanisms and clinical consequences. Lancet Infect. Dis. $2,73-85$.

Sardi, J.C.O., Scorzoni, L., Bernardi, T., Fusco-Almeida, A.M., Giannini, M.J.S.M., 2013. Candida species: current epidemiology, pathogenicity, biofilm formation, natural antifungal products and new therapeutic options. J. Med. Microbiol. $62,10-24$

Sher, A., 2009. Antimicrobial activity of natural products from medicinal plants. Gomal J. Med. Sci. 7, 72-78.

Shojaii, A., Fard, M.A., 2012. Review of pharmacological properties and chemical constituents of Pimpinella anisum. Int. Sch. Res. Network - ISRN Pharm. 2012, 1-8.

Singh, A., Duggal, S., Kaur, N., Singh, J., 2010. Berberine: alkaloid with wide spectrum of pharmacological activities. J. Nat. Prod. 3, 64-75.

Tsai, P.-W., Chen, Y.-T., Hsu, P.-C., Lan, C.-Y., 2013. Study of Candida albicans and its interactions with the host: a mini review. BioMedicine 3, 51-64.

Uzun, E., Sariyar, G., Adsersen, A., Karakoc, B., Otük, G., Oktayoglu, E., Pirildar, S. 2004. Traditional medicine in Sakarya province (Turkey) and antimicrobial activities of selected species. J. Ethnopharmacol. 95, 287-296.

White, T.C., Marr, K.A., Bowden, R.A., 1998. Clinical, cellular, and molecular factors that contribute to antifungal drug resistance. Clin. Microbiol. Rev. 11, 382-402.

Wiegand, I., Hilpert, K., Hancock, R.E.W., 2008. Agar and broth dilution methods to determine the minimal inhibitory concentration (MIC) of antimicrobial substances. Nat. Protoc. 3, 163-175. 